\title{
Learning and Teaching with the UK Census
}

\section{Background}

Through a number of strategic investments by the UK funding bodies for further and higher education.and the research councils, the UK academic community has access to an electronic Collection of Historical and Contemporary Census Data and Resources (CHCC). Individual datasets have been used extensively in research but they have been widely under-used in learning and teaching. To address this issue, the Joint Information Systems Committee (JISC), under its Learning and Teaching Programme, has funded a project to develop learning and teaching materials based on the CHCC. The JISC is a strategic advisory committee working on behalf of the funding bodies for UK tertiary education (FE and HE). This role allows it to provide a centralised and co-ordinated direction for the development of the infrastructure and services needed to support this sector in exploiting ICT for its learning, teaching and research activities. As part of its remit, JISC promotes the innovative application and use of information systems and information technology in tertiary education across the UK, by funding development projects and the creation of high quality materials for education. Currently JISC, in line with other UK initiatives, is funding a series of development projects to create high quality resources, which can be directly integrated into learning and teaching. The outcomes from these JISC funded projects will feed into the Information Environment being developed by JISC, to deliver resources to students, teachers and researchers in meaningful ways (Ingram, 2002).

The $\mathrm{CHCC}$ project is a multi-partner venture involving six partners from four UK Universities; Essex, Glasgow, Leeds and Manchester. The project started in October 2000 and will run until September 2003. Further details can be found at the website <http://www.chcc.ac.uk/>. For details about other projects that are funded under the JISC's Learning and Teaching Programme see Carter et al., 2002, or the website <http://www.jisc.ac.uk/dner/ development/programmes/learnteach.html>

\section{What is the CHCC?}

The first modern Census in the UK was taken in 1801, with a Census being conducted once every ten years since then, with the exception of 1941. The last Census was taken on $29^{\text {th }}$ April 2001, with plans to make the first statistics available in 2003. The National Statistics web site is an excellent source of detailed information about the UK Census <http:// www.statistics.gov.uk>.

Developments in data collection and provision in recent years have resulted in the UK academic community having free-at-the-point-of use access (subject to undertaking of agreements for terms and conditions of use) to a wide range of digital Census datasets. The first paper in this session outlines issues concerned with access to these datasets in more detail. (Bell, 2002). The Collection of Historical and Contemporary Census Data and Resources (CHCC), as outlined below, is part of a much fuller collection. It is important to note that the datasets comprising the $\mathrm{CHCC}$ are physically located in three different locations, and supported by three different support services.

The CHCC refers to the following datasets:

- $\quad$ The Census Area Statistics (CAS) from the 1991, 1981 and 1971 Census of Population. These are aggregated counts for a variety of geographical areas, such as county, district, ward and smaller areas. The 2001 Census Area Statistics will become available in 2003.

- $\quad$ The Samples of Anonymised Records (SARs) released for the first time from the 1991 census. These are samples of individual census returns both for individuals and households. The SARs for 2001 will also become available in 2003. For further information about the SARs refer to the website at <http: //www.ccsr.ac.uk>.

- The Historical Censuses Collection comprises individual-level data from the 1851 Census ( $2 \%$ sample) and 1881 Census (100\% sample) and aggregate-level data from nineteenth and early twentieth century printed census reports. For further details see <http: //hds.essex.ac.uk/chcc.asp> 
The CHCC provides the most comprehensive and geographically detailed set of statistics relating to people and housing in the UK. The 1991 Census covered a wide range of topics, which describe the characteristics of the UK population: demography, households, families, housing, ethnicity, birthplace, migration, illness, economic status, occupation, industry, workplace, transport mode to work, car ownership and language. The CHCC thus provide a unique source of information for students wishing to explore important social, demographic and economic issues, in modern or historical contexts. The strategic importance of the Census means that students from a wide range of academic disciplines will benefit greatly from a working knowledge of how to access and analyse these statistics.

Individual datasets from the $\mathrm{CHCC}$ have been widely used in research (for example, see http://www.ccsr.ac.uk publications/sarpub.htm $>$ for list of SARs related publications). However, the data have been less widely used in learning and teaching programmes. A number of factors have contributed to this: requirement for registration prior to data use; distributed nature of the census datasets; barriers to access due to hard-to-use interfaces; lack of knowledge about the existence of datasets and their potential for learning and teaching; lack of learning materials suitable for student use across disciplines. For an excellent summary of barriers facing teachers who use numeric data see the report by Rice et. al, 2002. We also reported on barriers to the use of the Census Area Statistics at IASSIST in 1999 (Carter and Bullen, 1999). The CHCC project has developed clear aims, objectives and outputs to respond to these barriers, as detailed below.

\section{Aims, Objectives and Outputs}

The primary aim of the project is to develop the $\mathrm{CHCC}$ into a major learning and teaching resource.

The key objectives to assist in achieving this aim are to:

1. Promote increased and more effective use of network based data services for problem-based learning and student project work across a broad range of teaching programmes;

2. Develop an integrated web-based learning and teaching system that links together data extraction and visualisation/exploration tools with comprehensive learning and teaching resources;

3. Significantly increase the Census user base by increasing use of the $\mathrm{CHCC}$ in learning and teaching;

4. Build new user communities by promoting increased awareness of the $\mathrm{CHCC}$ and its learning and teaching potential;
5. Improve the productivity of teachers by significantly reducing the overheads required to incorporate Census data related resources into learning and teaching programmes;

6. Improve access to key primary data related resources;

7. Minimise delays in getting the key 2001 Census outputs used in learning and teaching.

Four main outputs will be delivered from this project:

1. A range of learning and teaching resources for teachers and learners (tutorials, exercises, exemplarbased studies);

2. A Census resource discovery system to facilitate discovery of Census data and associated learning and teaching resources;

3. Improved web-based interfaces for data extraction/ visualisation suitable for student use;

4. Enhancement of the $\mathrm{CHCC}$ through adding and linking other information.

This paper reports on the development of these outputs, focusing on the learning and teaching materials and the Census resource discovery system.

\section{Learning and Teaching Resources}

A series of learning materials ('units') are being developed both by the project team, and commissioned by distinguished authors who have used Census data in their teaching. The units are designed to encourage a 'pick and mix' approach; so that a teacher can choose from a portion of a single unit (perhaps a simple graphic illustrating a statistical distribution of, for example, unemployed males), through to several units built into a module. The units can be used for both classroom-based and online learning, and can thus be used both by teachers and directly by students for independent learning. Such flexibility was a key requirement behind the development of the units and indicates our direct response to feedback from user consultation established at the start of the project. Another key requirement elicited from user consultation was the need to allow for customisability of the units. Authors provide the materials under a non-exclusive licensing agreement, which permits a teacher to alter the materials providing s/he credits the source and author of the original unit. Due to conditions of funding the materials are available through restricted access to UK Further and Higher education sites only. 


\section{Consultation}

The development of all learning and teaching materials is underpinned by a process of consultation and formative evaluation with potential end users (teachers and students). The first CHCC user consultation workshop was held in January 2001, just after the project began. The feedback from this workshop was crucial in guiding our development of the learning and teaching units. Several workshops have been held subsequently in which the first units have been piloted. The feedback received during these workshops is being used to improve upon existing units and assist in the development of future units. A period of piloting is currently taking place, in which the units are being tested in live teaching environments. Evaluation from these pilot studies will be fed into a project report, and used to further enhance the materials.

\section{Data specific units}

Two types of materials are in development. The first are 'data specific', that is, they are based on sets of data from the CHCC (the CAS, the SARs or the HCC). For UK access these can be viewed at <http://www.chcc.ac.uk/ ltlinks.html >. It has been necessary to restrict access to users registered at $\mathrm{UK} \mathrm{HE}$ and $\mathrm{FE}$ institutions due to the terms and conditions of the project's funding.

\section{CAS units}

These resources provide a range of teaching and learning materials that cover many aspects of contemporary Census Area Statistics (CAS). Each resource has been categorised into one of three types: Census basics, Census methods and Census applications. A guide to the level of difficulty covering beginners, intermediate and advanced users has also been specified. This should help the teacher or learner choose an effective pathway through the resources. For further details about the units, see <http://www.chcc.ac.uk/ CAS/resources.html>, <http://www.ccg.leeds.ac.uk/chcc/ resources.html>

\section{SARs units}

These units are being developed around two main themes

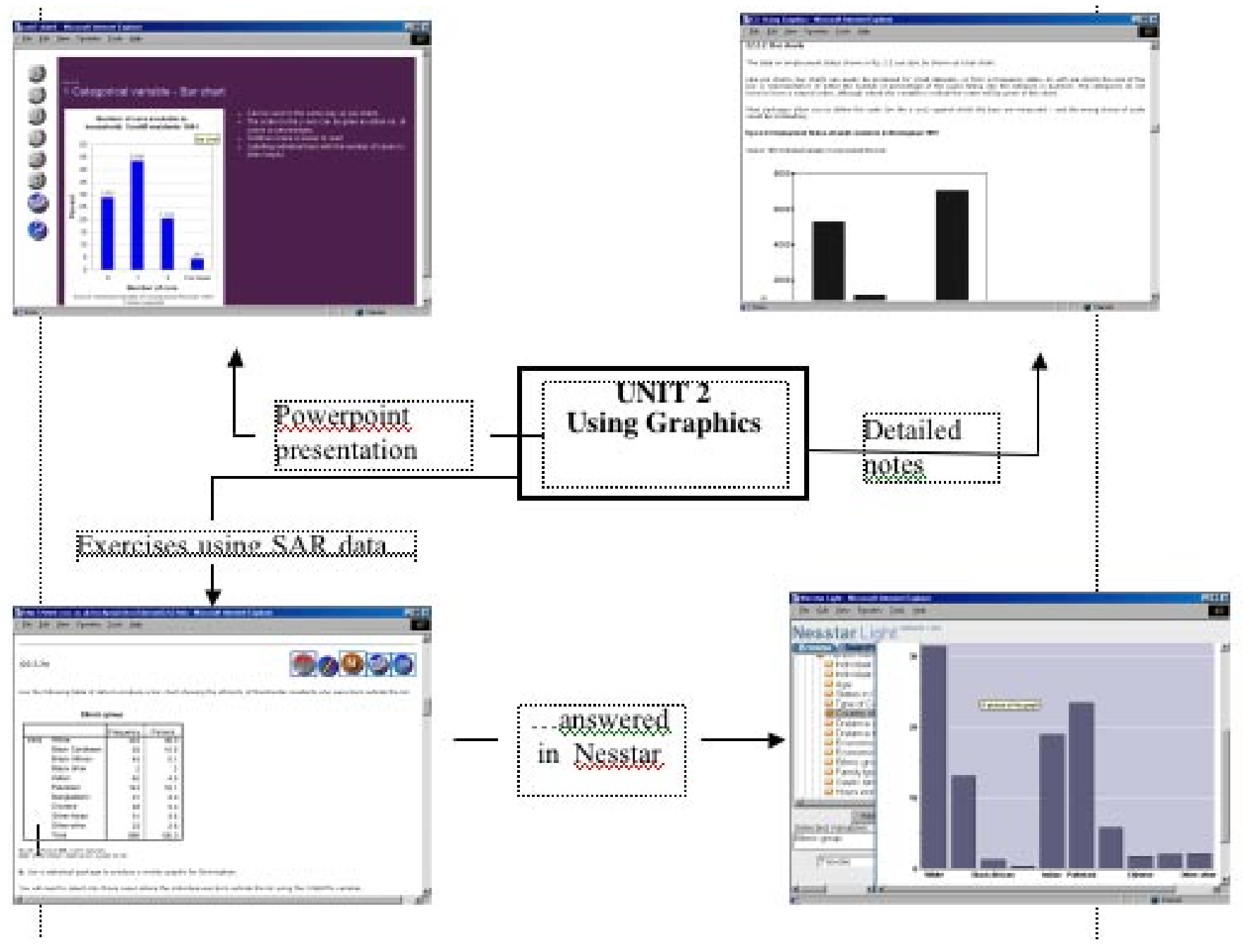


- Introductory data analysis units covering a wide range of topics starting from basic exploratory techniques through to more formal methods of statistical analysis.

- Substantive issues units covering more substantive discipline-specific topics.

All units have a common and flexible format, that can be readily adapted for use in classroom teaching and selfstudy. Each unit comprises three types of materials:

1. Overview - designed for use by lecturers; suitable for a half hour lecture.

2. Detailed notes - more detailed notes with a greater degree of statistical content, designed to supplement teachers' notes and suitable for student self learning.

3. Practical exercises - generic and software specific exercises, suited to incorporation in lessons or for homework.

Figure 1 illustrates the structure of the SAR methodological units, each of which incorporates a presentation (in this case, on the use of graphics), supported by detailed explanatory notes and exercises. In this example, a slide in the presentation introduces the use of bar charts. This provides the platform for a more detailed 'text-book' type explanation of bar charts and some linked exercises that enable students to explore the construction and interpretation of bar charts with some real data. Exercises vary in the level of difficulty and format, and include both computer and non-computer based exercises. For computerbased exercises, Nesstar provides a user-friendly on-line interface by which to undertake exercises on subsets of SAR data.

For further information about these units, including details of which are ready for piloting, see <http://www.ccsr.ac.uk/ rschproj/chcc/topics.htm >

\section{HCC units}

Units on the following topics are under development under the main theme of 'British History and the Census': understanding the nineteenth century census; household and family structure; migration in the nineteenth century; urbanisation; social status; work and employment; using the census for local history; skills. For further information about these units, see < http://chcc.gla.ac.uk/ie_index.php >

\section{Combined units}

The second type of material that will be developed is based on common topics across the census datasets contained in the CHCC. Combined units include introductory resources that are developed jointly by the project partners, and include links to the datasets. These units are in the early stages of development. The topics fall into three main areas:

1. What is the Census?

These units include: overview; census topics; the census questionnaire; census geography; coverage; methods of data collection and coding; census outputs; the census elsewhere.

2. Using the Census

These units include: confidentiality; data availability and dissemination; individual versus aggregate data; change over time.

3. Uses of the Census

These units include: key users and uses of CAS; key users and uses of SARs; key users and uses of HCC; what future the census?

\section{Web interfaces}

The efforts to develop teaching materials around the census data sets have been considerably enhanced by a dramatic improvement in the ease and flexibility by which users can access the underlying data. For example, when SARs were first released, their use in teaching was seriously limited by the need for users to be familiar with a specialist statistical package, such as SPSS, and to access the data via mainframe computer. The situation got better as the improving specifications of PCs enabled users to put SAR data files directly on to their desktops. However, the requirement to use a specialist statistical package still meant the data were inaccessible to many users. As part of the $\mathrm{CHCC}$ project, it has been possible to incorporate new and user-friendly web-interfaces to Census data, such as Nesstar (see Figure 1), opening up the teaching materials to a much wider user group.

Development work is also taking place to enable the CAS datasets to be visualized online, using interactive exploratory data visualization software. This software, called Descartes (see www.mimas.ac.uk/descartes for a sample dataset), has been developed at the Fraunhofer Institut Autonome Intelligente Systeme (FhG AIS) < http: / www.ais.fraunhofer.de $>$. It has been developed for the project, to improve access to the CAS by providing online mapping of census datasets in a web browser.

\section{Census Resource Discovery System}

The Census Resource Discovery System will facilitate resource discovery of both census data and the associated learning and teaching materials. It will provide a flexible, consistent, integrated interface to the learning and teaching materials and a mechanism for effective resource discovery across the learning and teaching materials and the census data. The main goals of the system are to: allow students, teachers and researchers to discover and locate census data and associated learning and teaching resources; provide links to on-line census data and associated learning and 
teaching resources; and provide a means for census data providers to publicise and propagate the use of their census data holdings and associated learning and teaching resources.

The system will provide a web interface to 'search' and 'discover' census data and associated learning and teaching resources through the entry of any combination of a subject keyword, a geographic area (England, Wales, Scotland, or Northern Ireland), a time period (date or span of dates) or a resource type (aggregate-level data, individual-level data, or learning and teaching resource). Users will also be able to browse hierarchical lists of census data and associated learning and teaching resources ordered by subject, geography, time-period or resource type. A list of items matching the browse or search criteria will be returned and users will be able to select and view the full record for one or more items simultaneously. Tools for project partners to add, modify and delete metadata records are being developed and users will be able to maintain a user profile to store query definitions for future use.

The DDI Codebook standard is being used to describe census data sets and the IMS Learning Resource Metadata Specification is being used to describe learning and teaching materials. The European Language Social Science Thesaurus is the source for subject keywords. An SQLServer database is being used to hold the metadata and Java technologies are being used for the web interfaces. A Cheshire Z39.50 target will be used to ensure integration with the JISC Information Environment. The Census Registration Service and Athens Single Sign On will allow users to move seamlessly between the different census data sets regardless of census data provider.

\section{References}

Bell, Lucy "Let Us Bring You to Your Census: Recent Developments in UK Census Data Provision." Paper presentation in Delivering the UK Census; Web-based Access, IASSIST 2002, Connecticut, US, 10-14 June, 2002.

Carter, Jackie et al. "Enhancing use of JISC data services." Vine 126, pp.40-47, 2002

Carter, J and Bullen, N. I "Overcoming barriers to the use of the Census through interactive visualization." Paper presentation in GIS and Social Science Data Access Over the Net, IASSIST 1999, Toronto, 17-21 May 1999.

Ingram, Caroline “JISC Development." Vine 126, pp.3-6, 2002

Hayes, J. and Carter, J. "Web-mapping the Census: Developing Interactive Interfaces for Learning and Teaching." Society of Cartographers Bulletin, Vol 35, No2, 2002
Rice, R., Burnhill, P., Wright, M. and Townsend, S. "An enquiry into the use of numeric data in learning and teaching" [computer file]. Edinburgh: Edinburgh University, September 2001 http://datalib.ed.ac.uk projects/datateach/report/

* Dr Jackie Carter, CHCC Project Manager, MIMAS, Manchester Computing, University of Manchester, email: j.carter@man.ac.uk

Dr Mark Brown, Deputy Director CCSR (Centre for Census and Survey Research), University of Manchester, UK

Cressida Chappell, Head of the History Data Service, UK Data Archive, University of Essex, UK 


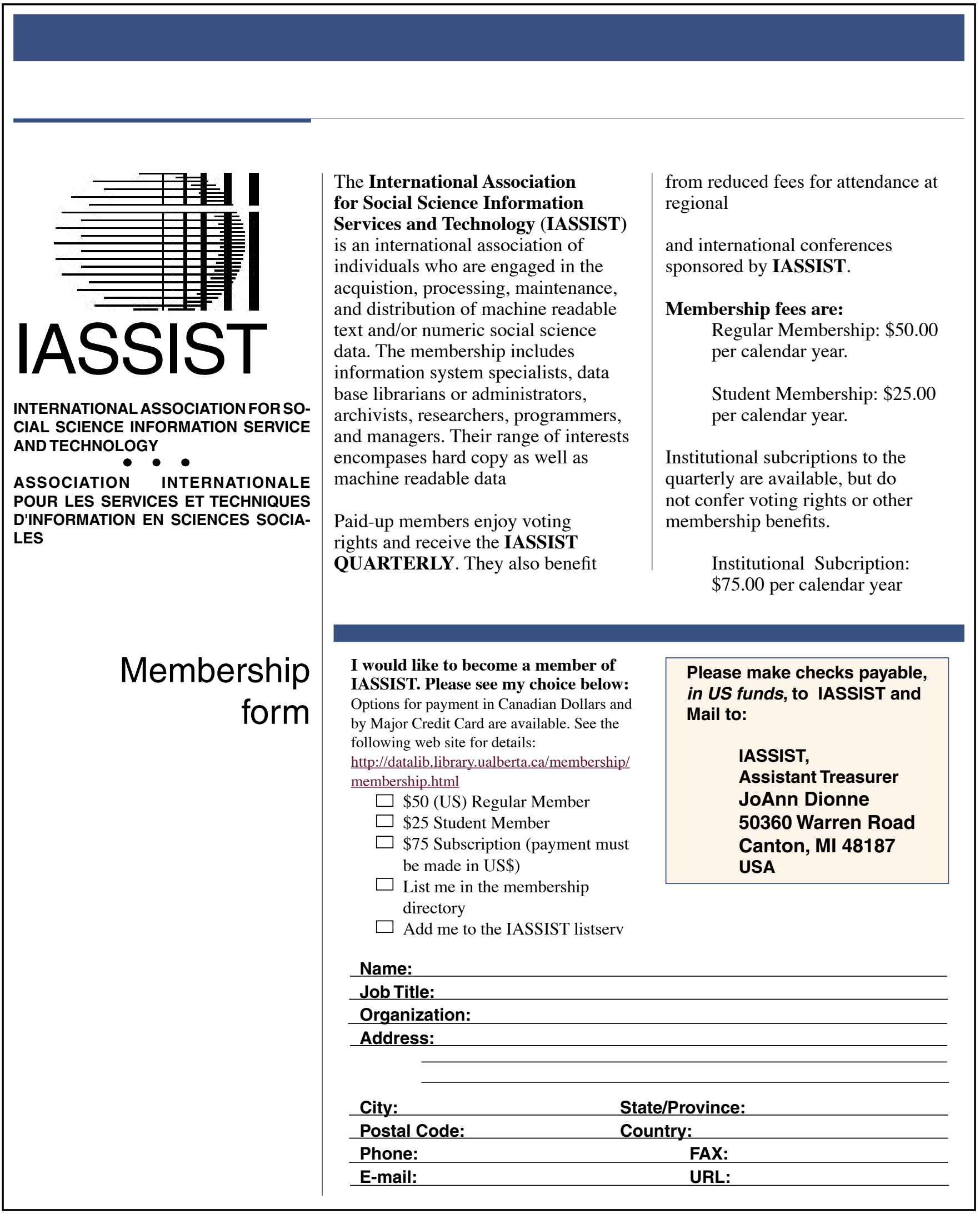

